\title{
Physico-chemical and quality evaluation of tomato ketchup during storage
}

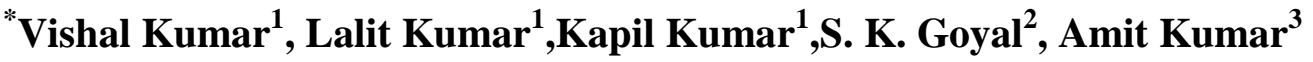 \\ andGarima Jain ${ }^{4}$ \\ ${ }^{1}$ Deptt. of Agric. Engg.and Food Technology, SVPUAT, Meerut (U.P.) \\ ${ }^{2}$ KVK, Institute of Agric. Sciences, BHU, RGSC, Barkachha, Mirzapur(UP) \\ ${ }^{3}$ Department of Food Science and Technology, ShriVenkateshwara University, Gajraula \\ ${ }^{4}$ Bhikaji CamaSubharti Institute of Hotel Management, SVS University, Meerut \\ *Email: vishalkumarsingh129@gmail.com
}

\begin{abstract}
A comparative study was done to determine the most suitable storage conditions. The selected quality and parameters of tomato ketchup were determined, the tomato slices was treated with KMS, sodium benzoate and control and dehydratedin cabinet tray dryer at $65{ }^{0} \mathrm{C}$ for preparation of ketchup. The ketchup stored in the refrigerator $\left(5^{\circ} \mathrm{C}\right)$ samples was found superior as compared to the room temperature storage. A gradual increase in Total Soluble Solids (TSS) and $\mathrm{pH}$ was observed during storage whereas acidity and ascorbic acid were decreased.
\end{abstract}

Keyword: Dehydrated tomato, ketchup, cabinet tray dryer, KMS and Sodium benzoate.

Paper cited:Kumar, V., Kumar, L., Kumar, K., Goyal, S.K., Kumar, A. and Jain, G. (2015). Physico-chemical and Quality evaluation of tomato ketchup during storage.South Asian Journal of Food Technology and Environment, 1(3\&4): 250-255.

Received: 07/10/2015 Revised: 25/10/2015 Accepted 30/10/2015

\section{Introduction}

\section{Tomatoes}

(LycopersiconesculentumL.var) are the world's most commercially produced and used vegetable crop (Ensmingeret al., 1994). The annual Indian production of tomatoes has been estimated at 7.277 million tonnes in an area of about 0.458 million hectares. It is very important in the economic point of view and hence the global production of tomatoes (fresh and processed) has been increased by $300 \%$ in the last four decades (FAO, 2005) and the leading tomato producers are in both tropical and temperate regions (Dhaliwalet al., 2003).

Worldwide, tomatoes are considered an important agricultural crop and an integral part of the human diet. Although tomatoes are commonly consumed fresh, over $80 \%$ of the tomato consumption comes from processed products such as tomato juice, ketchup and sauce. Recent studies have indicated the potential health benefits of a diet that is rich in tomatoes. Lycopene, a major carotenoid without provitamin an activity, present in red tomatoes, is considered responsible for their beneficial effects (Shi et al., 1999; Raoet al., 1998).Comparing with other natural antioxidants in plant tissues, carotenoids are relatively heat stable even after intense or prolonged heat treatment such as sterilization processes or cooking (Nicoliet al., 1999). However, during the processing and subsequent storage of products the content of carotenoids falls down and the color changes. The overheated or expired products have typical brown color and various off-flavors and oxidized flavor caused by low molecular compounds produced by oxidation of carotenoids and other lipids. The degradation reaction within the processing starts with cistrans isomerisation, fresh tomatoes contain alltrans lycopene, the processed tomato products contain between $1.7 \%$ and $10.1 \%$ cis-isomers (Shi and Mageur, 2000).

According to King and Zeidler (2004), tomato pomace contains $5.1 \%$ moisture, $11.9 \%$ fat, $26.8 \%$ protein and $26.3 \%$ crude fiber. Moreover, it contains $13 \%$ more lysine 
than soybean protein (AL-Betawi, 2005), a good source of vitamin $B$, fair source of vitamin $\mathrm{A}$ and no known anti-nutritive factors (Geisman, 1981).During the drying process and storage periods conditions, oxidative damage takes place in tomato (Zanoniet al., 1999; Toor and Savage, 2006; Sharma and Maguer, 1996; Zanoniet al., 2000). (Shi and Maguer, 2000), indicated that the main causes of lycopene degradation during processing and storage are isomerisation and oxidation.

Lycopene is also a potent neuroprotective (Hisaoet al., 2004), antiproliferative, anticancer (Gunasekeraet al.,2007), antiflammatory, cognition enhancer (Akboralyet al., 2007) and hypocholesterolemic agent (Risoet al., 2006). Lycopene has been under considerable investigation for its antioxidant benefits in treating various chronic human diseases like cancer, cardiovascular diseases, osteoporosis and diabetes (Rao and Rao1998).Ketchup is the product that is generally made from tomato paste after diluting on $15 \%$ of the soluble solids. It is flavored with sugar, salt, vinegar, spices, red pepper extract or other ingredients, such as onion, garlic, extracts of spiced herbs and the like (Drdák 1989, Intelmannet al., 2005). Commercial ketchup can have an extremely variable composition; nearly all manufacturers have a formula of their own which differs in some respects from those of other manufacturers.

\section{Materials and Methods}

\section{Samples preparation}

Fresh tomato was purchased from the local market Meerut. The tomato then thoroughly cleaned and to remove any dust particles attached to the surface. After slices the tomato were dipped into a solution $(\mathrm{ml})$ 1:4 ratio of second class preservative (sodium benzoate and potassium metabisulphite). The slices were then taken out from the solution and the surface moisture was wiped by blotting paper. The treated tomato sliced was dried by cabinet dryer and obtained dried slices followed to prepare the tomato powder than tomato ketchup.

\section{Drying of sample}

The pre-treated (KMS \& sodium benzoate) and untreated tomato slices were dried in the cabinet tray dryer. The tomatoes slices were placed uniformly on stainless steel trays $(80 \mathrm{~cm}$ length $\times 40 \mathrm{~cm}$ width and $1.37 \mathrm{~kg}$ weight) and drying were conducted at $65{ }^{\circ} \mathrm{C}$ temperature. The dried tomato flakes cooled at room temperature, then crushed by using blender to produce tomato powder for preparation of tomato ketchup. The tomato ketchup was stored forfurther investigation or analytical research. The process flow chart of preparation of tomato ketchup is given in Fig.1.

\section{Evaluation of physico-chemical properties}

Total Soluble Solids (TSS):TSS of tomato ketchup was measured by hand refractometer of range of $0-32^{\circ} \mathrm{Brix}$ recommended by Ranganna (2001).

pH: $\mathrm{pH}$ is the measurement of the logarithm of inverse of hydrogen ion concentration in the solution or $\mathrm{pH}$ is the measurement of $\mathrm{H}^{+}$ activity. The $\mathrm{pH}$ values were determined using the digital $\mathrm{pH}$ meter, as described by Ranganna (2001).

Acidity: Acidity may be referred as the percent total acid in any food substance. The organic acid is responsible for the sourness of fruit. Acidities of final products were determined using the method as recommended by Ranganna (2001).

Ascorbic acid:Ascorbic acid in ketchup is determined by titration recommended by Ranganna (2001).

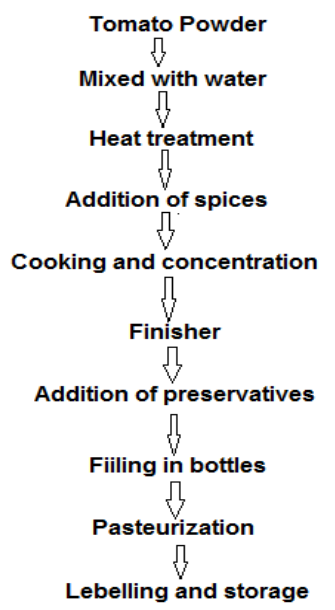




\section{Results and Discussion}

Effect on Acidity: The effectof storage on acidity of dehydrated tomatoes powder based ketchup is presented in Table 1 . The acidity of tomato ketchup samples treated before drying of tomato slices with potassium metabisulphite(KMS) and sodium benzoate (SB) in cabinet tray dryer at $65^{\circ} \mathrm{C}$.During refrigeration and room temperature storage conditions, it was observed that acidity of all the samples was decreased with increasing the storage periods. The lowest acidity of tomato ketchup during room temperature storage was found $1.51 \%$ (UT), $1.54 \%$ (KMS) and $1.53 \%$ (SB) at room temperature while $1.55 \%$ (UT), $1.60 \% \quad(\mathrm{KMS})$ and $1.54 \% \quad$ (SB)during refrigerationafter 120 days. The acidity significantly decreased with increased storage period.The study revealed that the ketchupmade from untreated tomato powder showed highest $(1.75 \%)$ acidity just after preparation and lowest $1.51 \%$ as well as 1.54 $\%$ storage of 120 days at room temperature and refrigerator $\left(5^{0} \mathrm{C}\right)$. From Table 1 showed that lowest temperature of storage or refrigeration increased that acidity as compared to room temperature. Similar results found by Kumar et al., (2015). In freshly ketchup, untreated sample had higher acidity followed by sodium benzoate and KMS while after 120 days storage acidity observed as $\mathrm{KMS}>\mathrm{SB}>\mathrm{UT}$ at room temperature and $\mathrm{KMS}>\mathrm{UT}>\mathrm{SB}$ in refrigeration at $5^{\circ} \mathrm{C}$.

Effect on pH:During refrigerator and room temperature storage conditions, it was observed, that acidity of all the samples was increased at $0,30,60,90$ and 120 days of storage conditions (Table 1). Among the parameters analyzed for the assessment of tomato quality, $\mathrm{pH}$ is very important because acidity influences the thermal processing conditions required for producing safe products. The highest $\mathrm{pH}$ found 4.6 (KMS) followed by 4.5 (UT), and 4.4 (SB) at room temperature after 120 days of storage whereas 4.6 (SB) followed by4.5 (UT), 4.4 (KMS) at refrigerator temperature after 120 days. The $\mathrm{pH}$ value increase with the effect of sugar concentration dilute in tomato ketchup samples and secondly effect of storage condition during room temperature and refrigerator conditions.Change in $\mathrm{pH}$ is directly related to change in acidity of samples. Similar findings were reported by Ahmad (1997) during his study on tomato concentrate. The acidic $\mathrm{pH}$ values obtained in this study is characteristic of most fruits and this influences the shelf life quality by restricting the micro flora to acid - tolerant microorganisms (Bracket, 1994).

Effect on TSS: TSS for fresh sample was found highest in SB (27.4) followed by KMS (25.7) and 23.0 in UT under room and refrigeration storage. The highest value was found 40.7 in the sample dried by cabinet tray dryer treated with sodium benzoate at room temperature. The TSS values were observed highest 40.7 for (SB),33.4 (UT) and 32.0 (KMS) at room temperature while 36.4 (KMS), 34.7 (UT) and 34.0 (SB) in refrigeration after 120 days of storage (Table 1). There was increased in TSS with increase in storage temperature. The TSS values were affected by the drying process. The increase value of TSS in the ketchup sample with effect of the sugar concentration include in the tomato ketchup sample.Actually the TSS value increased during storage condition.Increase in T.S.S. during storage may be due to acid hydrolysis of polysaccharides especially gums and pectin (Luh and Woodroof, 1975). The treatment of tomato before drying is also affect the TSS of ketchup if made from tomato powder. Sodium benzoate (SB) represented higher TSS followed by UT and KMS at room temperature whereas KMS $>\mathrm{UT}>\mathrm{SB}$ showed TSS in refrigeration after storage of 120 days. Effect on Ascorbic Acid (Vitamin-C): The effect of storage on ascorbic acid of dehydrated tomato powder based ketchup is presented in Table 1. The ascorbic acid of tomato ketchup samples treated before drying of tomato slices with potassium metabisulphite (KMS) and sodium benzoate (SB) in cabinet tray dryer at $65{ }^{\circ} \mathrm{C}$. During refrigeration and room temperature storage conditions, it was observed that ascorbic acid of all the samples 
was decreased with increasing the storage periods. The lowest ascorbic acid of tomato ketchup during room temperature storage was found 12 (UT), 14 (KMS) and 14 (SB) at room temperature while 14 (UT), 13 (KMS) and 14 (SB) during refrigeration after 120 days. The ascorbic acid significantly decreased with increased storage period. The study revealed that the ketchup made from untreated tomato powder showed highest (38) ascorbic acid just after preparation and lowest (12) storage of 120 days at room temperature and refrigeration $\left(5{ }^{0} \mathrm{C}\right)$. From the table 1 showed that lowest temperature of storage or refrigeration increased that ascorbic acid as compared to room temperature. The temperature influences the decreased in ascorbic acid. Similarly findings were reported by (smith and Hui, 2004) ascorbic acid may be destroyed by oxidation, especially at higher temperature. Its stability is greatly influenced by temperature, oxygen and metal ion content. Vitamin-C is the most labile of the nutrients, so its degradation is used as an indicator of quality.

Table 1: Effect of acidity, pH and TSS of the tomato ketchup samples during storageconditions

\begin{tabular}{|c|c|c|c|c|c|c|c|c|c|}
\hline \multicolumn{10}{|c|}{ Room Temperature } \\
\hline \multirow{2}{*}{$\begin{array}{c}\text { Storage } \\
\text { Periods(days) }\end{array}$} & \multicolumn{3}{|c|}{ Acidity (\%) } & \multicolumn{3}{|c|}{$\mathbf{p H}$} & \multicolumn{3}{|c|}{ TSS ( ${ }^{0}$ Brix) } \\
\hline & UT & KMS & S. B. & UT & KMS & S. B. & UT & KMS & S. B. \\
\hline 0 & 1.75 & 1.72 & 1.74 & 3.5 & 3.8 & 3.6 & 23.0 & 25.7 & 27.4 \\
\hline 30 & 1.70 & 1.69 & 1.71 & 3.9 & 4.0 & 3.8 & 25.0 & 27.4 & 29.3 \\
\hline 60 & 1.67 & 1.63 & 1.64 & 4.2 & 4.2 & 4.1 & 28.1 & 29.6 & 31.2 \\
\hline 90 & 1.60 & 1.58 & 1.55 & 4.4 & 4.5 & 4.3 & 30.5 & 31.2 & 33.4 \\
\hline 120 & 1.51 & 1.54 & 1.53 & 4.5 & 4.6 & 4.4 & 33.4 & 32.0 & 40.7 \\
\hline \multicolumn{10}{|c|}{ Refrigerator $\left(5^{0} \mathrm{C}\right)$} \\
\hline \multirow{2}{*}{$\begin{array}{c}\text { Storage } \\
\text { Periods(days) }\end{array}$} & \multicolumn{3}{|c|}{ Acidity (\%) } & \multicolumn{3}{|c|}{ pH } & \multicolumn{3}{|c|}{ TSS ( ${ }^{0}$ Brix) } \\
\hline & UT & KMS & S. B. & UT & KMS & S. B. & UT & KMS & S. B. \\
\hline 0 & 1.75 & 1.72 & 1.74 & 3.5 & 3.8 & 3.6 & 23.0 & 25.7 & 27.4 \\
\hline 30 & 1.72 & 1.70 & 1.70 & 3.8 & 3.9 & 3.8 & 27.5 & 29.7 & 32.5 \\
\hline 60 & 1.69 & 1.67 & 1.65 & 4.0 & 4.0 & 4.2 & 30.6 & 31.4 & 35.9 \\
\hline 90 & 1.60 & 1.64 & 1.58 & 4.3 & 4.2 & 4.5 & 32.4 & 33.8 & 37.4 \\
\hline 120 & 1.55 & 1.60 & 1.54 & 4.5 & 4.4 & 4.6 & 34.7 & 36.4 & 34.0 \\
\hline
\end{tabular}

Table 2: Effect of ascorbic acid of thetomato ketchup samples during storage conditions

\begin{tabular}{|c|c|c|c|c|c|c|}
\hline \multirow{2}{*}{$\begin{array}{c}\text { Storage Periods } \\
\text { (days) }\end{array}$} & \multicolumn{3}{|c|}{ Room Temperature } & \multicolumn{3}{c|}{ Refrigerator (50) } \\
\cline { 2 - 7 } & UT & KMS & S. B. & UT & KMS & S. B. \\
\hline 0 & 32 & 36 & 38 & 32 & 36 & 38 \\
\hline 30 & 26 & 24 & 24 & 24 & 31 & 30 \\
\hline 60 & 22 & 20 & 20 & 20 & 27 & 25 \\
\hline 90 & 17 & 16 & 16 & 16 & 19 & 18 \\
\hline 120 & 12 & 14 & 14 & 14 & 13 & 14 \\
\hline
\end{tabular}

(UT: Untreated; KMS: Potassium metabisulphite; SB: Sodium benzoate) 
The losses of ascorbic acid is probably attributable to oxidation of ascorbic acid to dehydroascorbic acid followed by hydrolysis of the latter to 2,3-diketogluconic acid, which than undergoes polymerization to other nutritionally inactive products (Dewantoet al., 2002).

\section{Conclusion}

It was conclusion of dehydrated tomato powder based ketchup could be stored at room temperature and refrigeration $\left(5^{\circ} \mathrm{C}\right)$ for 120 days. In this study ketchup produced by tomato powder than after analysis on the basis of physicochemical other properties of these ketchup samples. However, a gradual increase in Total Soluble Solids (TSS) and $\mathrm{pH}$ was observed during storage whereas acidity and ascorbic acid were decreased.

\section{References}

1. Ahmad, A., (1997). Chemical preservation of tomato concentrate prepared by cold break method. M.Sc. Thesis, Dept. Food Technol. Univ. Agric. Faisalabad.

2. Akboraly, N.T., Faure, H., Gourlet, V., Favier, A. and Berr, C. (2007). Plasma carotenoid levels and cognitive performance in an elderly population: results of the EVA Study. Journals of Gerontology Series A: Biological Sciences and Medical Sciences. 62: 308316.

3. Al-Betawi, N.A., (2005). Preliminary Study on Tomato Pomace as Unusual Feedstuff in Broiler Diets. Pakistan Journalof Nutrition, 4: 57-63.

4. Bracket, R.E. (1994). Microbiological spoilage and pathogens in minimally processed fruits and vegetables; Wiley, R. C. (Ed.), Chapman and Hall: New York, pp. 269-312.

5. Dewanto, V., Wu, X., Adom, K.K., and Liu, R.H. (2002). Thermal processing enhances the nutritional value of tomatoes by increasing total antioxidant activity. Journal of Agriculture and of Food Chemistry, 50: 3010-3014.

6. Dhaliwal, M.S., Kaur, P. and Singh, S. (2003). Genetical Analysis of Biochemical Constitution in Tomato. Advances in Horticultural Sciences. 17 (1): 37-41.

7. Drdák, M. (1989). Technológiarastlinnýchneúdržnýchpotra vín. ALFA, Bratislava. Ferrer E, Alegría A, Farré R, Abellán P, Romero F (2002). Journal of Chromatography A, 947: 8595.

8. Ensminger, A.H., Ensminger; M.E., Konlande, J.E. and Robson, J.R.K. (1994). Foods and nutrition encyclopedia. CRC Press, Boca Raton, Fla.

9. FAO (2005). Homepage: http://www.fao.org.

10. Gesiman, J. R. (1981). Protein from tomato seeds. Ohio Report Res. Dev., 66: 92-94.

11. Gunasekera, R. S., Sewgobind, K., Desai S., Dunn, L., Black, H.S. and McKeehan, W.L. (2007). Lycopene and lutein inhibit proliferation in rat prostate carcinoma cells.

NutritionandCancer, 58: 171-177.

12. Hisao, G., Fong, T.H., Tzu, N.H., Lin, K.H.; Chou, D.S. and Sheu, J. R. (2004). A potent antioxidant, lycopene, affords neuroprotection against microglia activation and focal cerebral ischemia in rats. In Vivo, 18: 351- 356.

13. Intelmann,D., Jaros, D. and Rohm, H. (2005). Identification of color optima of commercial tomat o catsup. European Food Research and Technology, 221 (5): 662-666.

14. King, A.J. and Zeidler, G., (2004).Tomato Pomace May be a Good Source of Vitamin E in Broiler Diets. California Agriculture, 58(1): 658.

15. Kumar, T., Chandra, S., Samsher; Chauhan, N. and Singh, J. (2015). Effect of different hydrocolloids on the quality of ketchup during storage. South Asian 
Journal of Food Technology and Environment, 1(2): 152-159.

16. Luh, B.S. and Woodroof, J.G. (1975). Commercial Vegetable Processing. The AVI Publishing Company, Westport, Connecticut, USA. pp: 649- 650.

17. Nicoli, M.C., Anese, M. and Parpinel, M. (1999). Influence of processing on the antioxidant properties of fruit and vegetables. Trends in Food Science and Technology, 10 (3): 94-100.

18. Ranganna, S. (2001). Handbook of analysis and quality control of fruits and vegetable products. Tata McGraw Hill New Delhi.

19. Rao, A. V., Waseem, Z. and Agarwal, S. (1998). Lycopene Content of Tomatoes and Tomato Products and their Contribution to DietaryLycopene. Food Research International, 31(10): 737-741.

20. Rao, A.V. and Rao, L. G. (1998). Carotenoids and human health. Pharmacological Research, 55: 207216.

21. Riso, P., Visioli F., Grande, S., Guarnieri, S., Gardana, C. and Simonetti, P. (2006). Effect of a tomato-based drink on markers of inflammation, immunomodulation and oxidative stress. Journal of Agriculture and Food Chemistry, 54: 2563-2566.

22. Sharma, S. K. and Le Maguer, M. (1996). Kinetics of lycopene degradation in tomato pulp solids under different processing and storage conditions. Food Research International, 29(3-4): 309315.

23. Shi, J. and Le, Maguer, M. (2000). Lycopene in Tomatoes: Chemical and Physical Properties Affected by Food Processing. Critical Reviews in Food Science and Nutrition, 40 (1): 1-42.

24. Shi, J., Maguer, M.L., Kakuda, Y., Liptay, A. and Niekamp, F. (1999). Lycopene degradation and isomerisation in tomato dehydration. Food Research International, Vol.32 (1): 15-21
25. Smith, J.S. and Y.H. Hui, (2004). Food Processing, Principles and applications. Blackwell Publishing Company, USA.

26. Toor, R.K. and Savage, G. P. (2006). Effect of semi-drying on the antioxidant components of tomatoes. Food Chemistry, 94: 90-97.

27. Zanoni, B., Pagliarini, E. and Foschino, R. (2000). Study of the stability of dried tomato halves during shelf-life to minimize oxidation damage. Journalof theScience of Foodand Agriculture,80: 2203-2208.

28. Zanoni, B., Peri, C., Nani, R. and Lavelli, V. (1999): Oxidative Heat Damage of Tomato Halves as Affected by Drying. Food Research International, 31(5): 395-401. 